\title{
PEMBERDAYAAN TUTOR BKB DAN GURU PAUD MELALUI KETERAMPILAN STORYTELLING
}

\author{
Nila Fitria ${ }^{*}$, Suwardi $^{1}$ \\ ${ }^{1}$ Pendidikan Guru Pendidikan Anak Usia Dini, Fakultas Psikologi dan Pendidikan, \\ Universitas Al Azhar Indonesia, Jalan Sisingamangaraja,Kebayoran Baru, Jakarta Selatan 12110 \\ Email Penulis Korespondensi: nilafitria84@gmail.com
}

\begin{abstract}
Abstrak
Storytelling adalah sebuah teknik atau kemampuan untuk menceritakan sebuah kisah, pengaturan adegan, event, dan juga dialog. Program storytelling ini ditujukan bagi tutor BKB dan guru PAUD dikarenakan latar belakang pendidikan tutor BKB dan guru PAUD yang beragam. Adapun pelatihan yang dilakukan sebanyak 3 kali memberikan pengetahuan dan keterampilan storytelling kepada tutor $B K B$ dan guru PAUD. Adapun metode yang digunakan dalam pelatihan ini adalah bentuk intervensi dengan melakukan pelatihan sebanyak 3 kali. Pelatihan pertama ditujukan kepada tutor BKB dan guru PAUD untuk memberikan pengetahuan tentang storytelling. Pelatihan kedua, tutor BKB dan guru PAUD membuat buku cerita dalam bentuk bigbook. Kemudian tutor BKB dan guru PAUD mempraktekkan bagaimana cara bercerita secara peer teaching Pelatihan ketiga ditujukan kepada orang tua murid PAUD dan TK serta tutor BKB dan guru PAUD serta guru TK. Pelatihan ketiga ini bertujuan untuk memberikan pengetahuan pentingnya storytelling. Kemudian tutor BKB dan guru PAUD mempraktekkan bercerita di depan orang tua murid dan juga anak. Pengetahuan dan keterampilan tutor BKB dan guru PAUD terhadap storytelling meningkat dan program storytelling dapat dijadikan suatu pembiasaan yang dapat dilakuakn di sekolah. Sehingga minat membaca anak menjadi meningkat.
\end{abstract}

\section{Kata kunci: Anak, Storytelling, Tutor BKB}

\begin{abstract}
Storytelling is a technique or ability to tell a story, arrange scenes, events, and also dialogue. This storytelling program is intended for BKB tutors and PAUD teachers due to the diverse educational background of BKB tutors and PAUD teachers. The training was conducted 3 times to provide knowledge and storytelling skills to BKB tutors and PAUD teachers. The method used in this training is a form of intervention by conducting training 3 times. The first training was aimed at BKB tutors and $P A U D$ teachers to provide knowledge about storytelling. The second training, BKB tutors and PAUD teachers made storybooks in the form of a bigbook. Then BKB tutors and PAUD teachers practice how to tell in peer teaching The third training is aimed at parents of PAUD and TK students and BKB tutors and PAUD teachers and kindergarten teachers. This third training aims to provide knowledge of the importance of storytelling. Then BKB tutors and PAUD teachers practice telling stories in front of parents of students and children. Knowledge and skills of BKB tutors and PAUD teachers on storytelling have increased and the storytelling program can be used as a habit that can be done at school. So that interest in reading children becomes increased.
\end{abstract}

Keywords: BKB Tutor, Children, Storytelling 


\section{PENDAhUluaN}

Pendidikan Anak Usia Dini dalam Permen No. 137 tahun 2013 merupakan merupakan salah satu bentuk satuan pendidikan pada jenjang pendidikan anak usia dini yang pada hakekatnya adalah pendidikan yang diselenggarakan dengan tujuan untuk memfasilitasi pertumbuhan dan perkembangan anak secara menyeluruh atau menekankan pada pengembangan seluruh aspek perkembangan anak. Pendidikan anak usia dini dapat diselenggarakan melalui jalur pendidikan formal, non formal, dan informal. Pendidikan anak usia dini jalur pendidikan formal diselenggarakan pada Taman Kanak-Kanak (TK), Raudlatul Athfal (RA), atau bentuk lain yang sederajat rentang usia 4-6 tahun. Pendidikan anak usia dini jalur pendidikan nonformal diselenggarakan pada Kelompok Bermain (KB) rentang usia anak 2-4 tahun, Taman Penitipan Anak (TPA) rentang usia anak 3 bulan - 2 tahun, atau bentuk lain yang sederajat (Satuan PAUD Sejenis/SPS) rentang usia anak 4-6 tahun. Pendidikan anak usia dini jalur pendidikan informal diselenggarakan pada pendidikan keluarga atau pendidikan yang diselenggarakan oleh lingkungan bagi orang tua yang mempunyai anak usia 0-6 tahun.

Salah satu jalur pendidikan nonformal dalam bentuk lain yang sederajat untuk rentang usia anak 4-6 tahun adalah BKB PAUD. BKB PAUD (Bina Keluarga Balita) merupakan sebuah program dari pemerintah dalam rangka pembinaan keluarga untuk mewujudkan tumbuh kembang balita secara optimal. BKB ini adalah keluarga dan orangtua yang memiliki anak balita 0-5 tahun (BKKBN:2006). Waktu pembelajarannya pun beragam tergantung ruang kelas yang mereka miliki. Sehingga waktu pembelajarannya bergantian sesuai dengan rentang usia anak.

Tutor BKB yang mengajar di BKB PAUD adalah ibu-ibu PKK dengan latarbelakang pendidikan yang beragam mulai dari lulusan SMA, D3, dan S1. Mereka memiliki pengetahuan yang minim tentang ilmu Pendidikan Anak Usia Dini. Dasar kemampuan mengajar didapatkan dari pengalaman menjadi orangtua. Sehingga kompetensi yang dimiliki guru BKB PAUD masih rendah dalam hal pengetahuan dan keterampilan mengajar. Hal tersebut teramati oleh peneliti pada salah satu BKB PAUD, dimana pembelajaran yang dilakukan masih menggunakan kertas dan pensil (pencil and paper). Pembelajaran yang seharusnya diterapkan belajar sambil bermain, tidak lagi menjadi hal yang penting. Nilai-nilai moral dan soft skill yang seharusnya dimiliki oleh anak usia dini tergantikan dengan kertas dan pensil.

Salah satu solusi yang akan dilakukan dalam rangka menanamkan nilai-nilai moral dan soft skill melalui storytelling. Guru dapat menanamkan nilai-nilai agama dan moral melalui storytelling. Melalui storytelling, anak dapat dapat membangun kosakata, menanamkan budi pekerti, mengajarkan nilai moral, dan mengembangkan imajinasi anak. Tentunya banyak manfaat yang didapatkan melalui storytelling. Bukan hanya kemampuan nilainilai moral yang meningkat melainkan aspek kognitif (ide) dan bahasa (kosakata) anak meningkat. Melihat permasalahan di lapangan, maka akan melakukan "Pemberdayaan Tutor BKB dan Guru PAUD melalui program storytelling. Pemberdayaan ini diharapkan dapat meningkatkan pengetahuan dam keterampilan tutor BKB dan guru PAUD dalam melakukan storytelling.

\section{METODE PELAKSANAAN}

Metode pengabdian masayarakat yang digunakan adalah metode deskripitif kuantitatif dengan desain Pre test-Post test Control Group Design. Dilakukan pengukuran sebelum (Pre test) dan sesudah (Post test) pemberian treatment.

Metode dalam kegiatan pengabdian masyarakat ini adalah dengan pelatihan sebagai sarana intervensi. Intervensi adalah suatu tindakan yang menghasilkan perubahan atau usaha untuk merubah seseorang, populasi, atau organisasi yang menjadi subjek evaluasi (Øvretveit,1998). Adapun tujuan dari intervensi adalah untuk menghasilkan suatu perubahan serta membuat perubahan dalam hidup seseorang (Øvretveit,1998).

Bentuk intervensi yang dilakukan adalah terkait "Pelatihan Storytelling bagi Tutor BKB" Pelatihan ini dilaksanakan di PAUD Raudlatul Azhar yang beralamatkan Jalan Sukarela 1 Kreo Kecamatan Larangan. Adapun peserta pelatihan ini adalah pengelola dan tutor BKB. Latar belakang pendidikan pengelola dan tutor BKB yang berada di kecamatan Larangan. Maka subjek yang diteliti berjumlah 8 tutor BKB. Adapun 8 tutor BKB terdiri dari 4 PAUD di 
kecamatan Larangan yaitu: PAUD Kemuning, PAUD Kenanga, PAUD Raudlatul Azhar, dan BKB PAUD Jambu Merah.

Kegiatan pelatihan ini telah dimulai bulan Desember 2017 - Agustus 2018. Adapun tahapan pelaksanaan kegiatan adalah sebagai berikut

\section{Persiapan}

Kegiatan ini dimulai dengan mempersiapkan materi-materi yang berkaitan dengan pelatihan yang akan diberikan. Adapun persiapan pelatihan storytelling ini mencakup:

A. Materi

Materi yang dipersiapkan bagi tutor BKB

PAUD, guru PAUD dan juga orang tua murid

PAUD. Materi tersebut mencakup:

1) Tutor BKB dan Guru PAUD,

Tutor BKB dan guru PAUD diharapkan memiliki pengetahuan tentang storytelling, teknik dalam storytelling, keterampilan dalam storytelling dan pentingnya storytelling kepada anak.

2) Orang tua

Orang tua diharapkan memiliki pengetahuan. tentang pentingnya storytelling kepada anak, dan keterampilan dalam storytelling.

B. Media

Media yang dibutuhkan dalam pelatihan storytelling mencakup: Infokus, laptop,buku gambar, krayon, lem, gunting, kertas origami, dan bigbook.

2. Pelaksanaan

Pelaksanaan pelatihan storytelling dilakukan dalam 3 kali pertemuan. Pelatihan 1 dan pelatihan 2 ditujukan kepada tutor BKB dan guru PAUD. Sedangkan pelatihan ke 3 ditujukan kepada tutor BKB dan guru PAUD dan orang tua murid PAUD dan TK

\section{HASIL DAN PEMBAHASAN}

Adapun hasil dari kegiatan pengabdian masyarakat ini adalah :

\section{a. Pelatihan ke 1}

Pelatihan 1 dilaksanakan pada hari Senin, 26 Maret dari pukul 08.00 - 13.00. pelatihan ini mengundang 4 PAUD di kecamatan Larangan yaitu: PAUD Kemuning, PAUD Kenanga, PAUD Raudlatul Azhar, dan BKB PAUD
Jambu Merah. Masing-masing perwakilan dari tutor PAUD berjumlah 2 guru. Materi 1 tentang Storytelling dan sebagai pemateri Dr. Suwardi, M.Pd yang dilaksanakan di PAUD Raudlatul Azhar dengan peserta pelatihan berjumlah 8 orang.

Dr. Suwardi, M.Pd menjelaskan tentang apa itu storytelling, unsur-unsur dalam storytelling, macam-macam storytelling, tujuan storytelling, dan manfaat dari storytelling. Setelah itu dilanjutkan dengan tanya jawab. Kemudian kami memberikan peralatan untuk membuat bigbook yang akan digunakan oleh guru PAUD.

Pada pertemuan pertama, tutor BKB dan guru PAUD diberikan pertanyaan terbuka, yaitu 1. Apakah tutor BKB dan guru PAUD sering bercerita di kelas?

2. Media yang digunakan ketika bercerita?

3. Tema cerita apa saja yang sering diceritakan kepada anak-anak?

4. Apakah guru menyampaikan pesan moral?

5. Kapan waktu yang dilakukan guru untuk bercerita?

Adapun hasil jawaban kepada guru PAUD disajikan dalam bentuk diagram batang berikut ini:

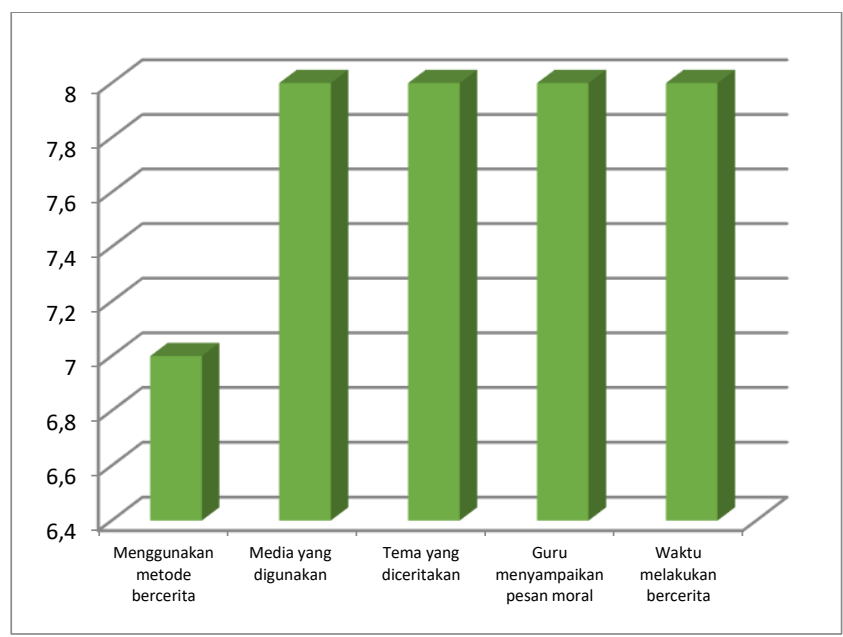

Gambar 1. Hasil kegiatan storytelling di PAUD

Dari 8 tutor BKB dan guru PAUD yang mengikuti pelatihan, 7 tutor $\mathrm{BKB}$ dan guru PAUD telah menggunakan metode bercerita dalam pembelajaran yang dilakukan ketika materi pagi sebanyak 5 guru diamana guru menjelaskan tentang tema yang akan dibahas, 1 orang guru melakukan pada kegiatan awal, kegiatan inti, dan kegiatan penutup, 2 orang guru melakukan bercerita pada kegiatan akhir. 8 orang tutor BKB dan guru PAUD menggunakan media dalam bercerita. 7 orang guru menggunakan buku cerita anak, 1 orang 
menggunakan boneka tangan. Selain itu terdapat media langsung seperti binatang (kura-kura, ayam, kelinci, dan lain-lain) Adapun tema yang disampaikan dengan metode bercerita, 2 guru menyatakan semua tema dapat disampaikan dengan metode bercerita. 2 guru bercerita ketika tema keluarga, 2 guru bercerita ketika tema diri sendiri, 1 tema binatang, dan 1 guru tidak menggunakan tema. Tentunya dalam bercerita terdapat pesan moral yang penting disampaikan kepada anak. 8 guru menyampaikan pesan moral dalam cerita kepada anak, dengan harapan anak dapat megetahu, memahami, dan meniru moral perilaku yang baik.

\section{b. Pelatihan ke 2}

Pertemuan selanjutnya untuk pelatihan ke 2 akan dilaksanakan di bulan Mei 2018. Pertemuan kepada guru PAUD untuk mempraktekkkan storytelling menggunakan bigbook yang dibuat. Masing-masing guru mempraktekkan bigbook yang dibuat. Dalam mempraktekkan storytelling yang didampingi oleh ibu Nila Fitria, M.Pd, Ibu Nila mengajarkan di mulai dari pemanasan mulai dari pundak, leher, punggung, dan iga-iga. Dilanjutkan dengan pernafasan dengan menggunakan diafragma, mendesis, dan bernafas dengan natural. Senam wajah dengan menggerakkan wajah dan pijat muka. Hal terpenting pula dalam storytelling yaitu olah vokal. Olah vokal menjadi hal yang penting, karena dalam storytelling harus dapat menggunakan beragam suara.

Setelah penjelasan dari Ibu Nila, maka guru PAUD satu persatu mulai mempraktekkan dari bigbook yang dibuat. Adapun isi dari bigbook yang dibuat oleh tutor BKB dan guru PAUD terdiri dari:

\section{Ide Cerita}

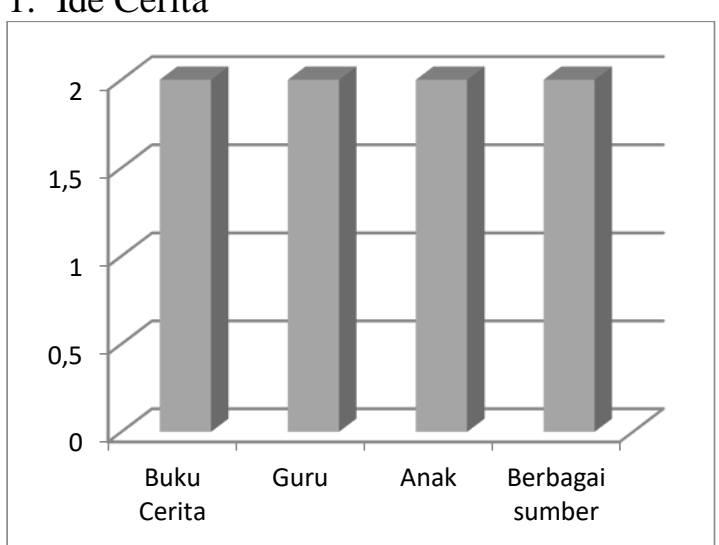

Gambar 2. Hasil Ide Cerita Membuat Bigbook
Adapun ide cerita yang dibuat oleh guru ketika membuat bigbook berasal dari 3 guru membuat bigbook ide cerita yang dihadirkan berasal dari buku cerita yang sudah ada, 2 guru ide cerita yang dihadirkan berasal dari ide guru sendiri dimana guru menciptakan cerita baru dalam membuat bigbook, 2 guru menghadirkan ide cerita dalam membuat bigbook dari permasalahan anak sehari-hari, dan 2 guru menghadirkan ide cerita dari berbagai sumber mencakup buku cerita, permasalahan anak, serta ide guru sendiri.

\section{Suara

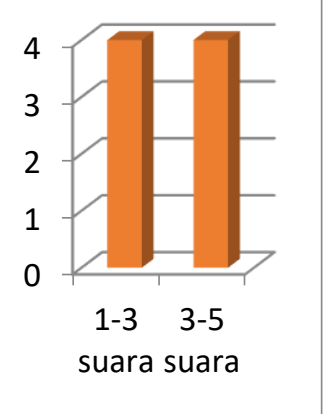 \\ Gambar 3. Hasil Ragam Suara}

Ragam suara yang dihadirkan guru ketika mempraktekkan storytelling yaitu 4 guru menggunakan 1-3 ragam sesuai dengan tokoh yang dibuat dalam bigbook. 4 tutor BKB dan guru PAUD menggunakan 3-5 ragam suara sesuai dengan tokoh yang dibuat dalam bigbook. Keragaman suara yang dihadirkan oleh guru merupakan salah satu bentuk kreativitas dalam melakukan storytelling

\section{Tokoh}

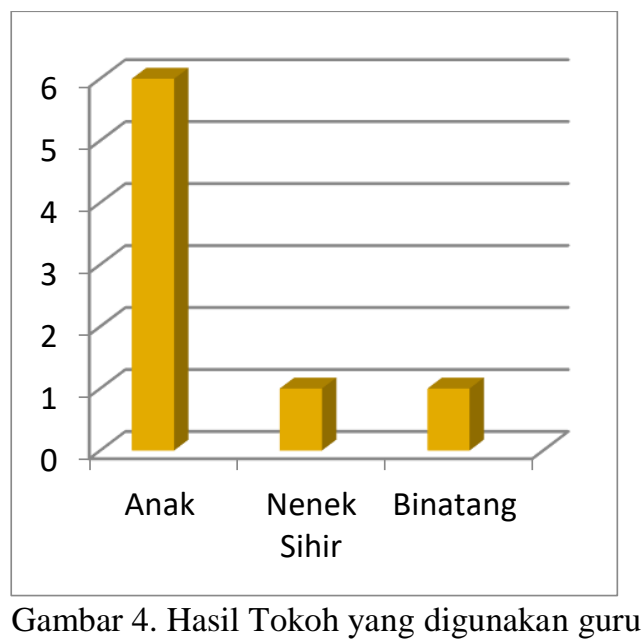

Dalam membuat bigbook, 6 tutor BKB dan guru PAUD menjadikan tokoh anak-anak yang 
dihadirkan dalam bigbook. Anak-anak dijadikan tokoh dengan alasan, anak sendiri yang menjadi contoh sehingga pesan moral lebih mudah diterima oleh anak. 1 guru menggunakan tokoh nenek sihir ketika membuat bigbook. Adapun alasan yang guru menjadikan nenek sihir sebagai tokoh karena nenek sihir memiliki karakter antagonis. Nenek sihir menjadi tokoh dalam bigbook karena nenek sihir merupakan bagian dari imajinasi anak-anak. 1 guru menjadikan tokoh beragam binatang karena binatang merupakan hal yang dekat dengan dunia anak. Sehingga anak mudah menerima karakter yang ada pada masing-masing binatang.

\section{c. Pelatihan ke 3}

Kegiatan penyuluhan yang dilakukan kepada orang tua murid dan guru PAUD dilaksanakan pada hari Jumat, 27 Juli 2018 di Mushola Raudlatul Azhar mulai pukul 08.00-11.00. Kegiatan penyuluhan kepada orang tua murid dan guru PAUD dengan tema "Pentingnya Storytelling bagi Anak Usia Dini" dihadiri 97 orang tua murid dan 12 guru. Kegiatan yang dibuka oleh miss Nisa sebagai MC kemudian dilanjutkan dengan kegiatan penyuluhan oleh Ibu Nila Fitria, M.Pd.

Ibu Nila Fitria, M.Pd menjelasakan perkembangan otak anak di masa golden age. Dimana 50\% otak anak berkembang dari usia 05 tahun kemudian 30\% berkembang ketika berusia 5-8 tahun. Storytelling merupakan kebutuhan anak dimana telinga sebagai organ dengar menjadi kosakata dengar. Kosakata dengar menampung beragam kosa kata sehingga anak memiliki kosakata bicara. Anak tampak terampil dalam berkomunikasi di lingkungan sosialnya. Kemampuan tersebut berlanjut menjadi kosakata baca. Anak mulai memahami kata-kata yang diucapkannya berasal dari hurufhuruf. Di tahap akhir, anak memiliki kosa kata tulis. Anak mulai memahami apa yang diucapkan dan dibaca dapat ditulis. Begitu pentingnya story telling, dari hasil penelitian dikatakan bahwa anak kelas 4 yang sejak dini dibacakan buku memiliki nilai 30 lebih tinggi dibandingkan anak-anak yang sesekali dibacakan buku. Pentingnya storytelling bagi anak menjadi salah suatu cara mempersiapkan anak untuk dapat membaca. Pembiasaan storytelling yang harus dilakukan oleh orang tua kepada anaknya menjadi salah satu hal yang penting. Dengan membiasakan storytelling kepada anak, merupakan salah satu cara membangun kosakata, mengkondisikan otak anak untuk mengasosikan membaca dengan kebahagiaan, menciptakan informasi, memberikan sosok panutan yang gemar membaca, menanam kegemaran membaca. Dengan harapan anak menjadi gemar membaca.

Setelah penyuluhan dari Ibu Nila Fitria, M.Pd dilanjutkan dengan sesi Tanya jawab. Pertanyaan dari salah satu orang tua yang bertanya " bagaimana membiasakan anak saya, yang setiap malam senang menonton youtube terutama tentang sapi?" kemudian Ibu Nila menjawab, anak yang sudah biasa nonton youtube tentunya memiliki kesenangan tersendiri. Kembali lagi kepada tujuan pengasuhan dari orang tua seperti apa? Sehingga orang tua dapat membiasakan hal-hal yang baik bagi tumbuh kembang anak.

Kegiatan penyuluhan ini bertujuan untuk memberikan pengetahuan kepada orang tua tentang pentingnya storytelling bagi anak. Hal tersebut sesuai dengan Gerakan Nasional Orang Tua Membacakan Buku (GERNAS BAKU). Gerakan ini mendukung pengembangan literasi anak melalui peran orang tua. Gerakan ini mendukung inisiatif dan peran keluarga dalam menumbuhkan minat baca anak melalui pembiasan di rumah, satuan PAUD, dan masyarakat. Tentunya gerakan ini mendukung minat baca anak dan mempererat hubungan emosional anak dengan orang tua.

\section{SIMPULAN DAN SARAN}

Berdasarkan hasil dari pelatihan dan pembahasan yang telah diuraikan, maka dapat disimpulkan bahwa :

Pengetahuan tentang story telling pada tutor BKB dan guru PAUD meningkat dilihat dari diterapkannya metode storytelling dalam kegiatan belajar mengajar walaupun terdapat pula tutor BKB yang belum menerapkan dalam kegiatan belajar mengajar.

Kemampuan tutor BKB dan guru PAUD dalam membuat buku cerita berupa bigbook menampilkan ide cerita yang ditampilkan dari berbagai sumber, baik itu buku, anak, binatang, dan benda sekitar. Ketika praktek storytelling, guru sudah melakukan berbagai ragam suara agar cerita yang dihadirkan lebih menarik untuk anak-anak sehingga terasa nyata ketika ditampilkan dengan ragam suara. Tokoh yang diambil ketika melakukan storytelling, tutor 
BKB menokohkan anak-anak langsung sebagai tokoh. Terutama kepada tokoh yang memiliki sikap positif.

Keterampilan tutor BKB dan guru PAUD dalam melakukan storytelling cukup baik. Tutor $\mathrm{BKB}$ dan guru PAUD mengembangan dengan alat peraga untuk menunjang kegiatn storytelling agar lebih menarik.

\section{UCAPAN TERIMA KASIH}

Ucapan terima kasih disampaikan kepada LP2M UAI yang telah mendanai kegiatan pengabdian masyarakat ini.

\section{DAFTAR PUSTAKA}

BKKBN. (2006). Pedoman Pembinaan Bina Keluarga Balita, Jakarta: BKKBN

Kementerian Pendidikan dan Kebudayaan. (2014). Peraturan Menteri Nomor 137 Tahun
2014 tentang Kurikulum PAUD, Jakarta:Kemdikbud

Kompas. dengan judul "Beda Mendongeng dan"ReadAloud", https://lifestyle.kompas.co $\mathrm{m} / \mathrm{read} / 2011 / 02 / 14 / 12093893 /$ beda.mendon geng.dan.quotread.aloudquot

Kusumo, Priyono. (2006). Terampil Mendongeng, Jakarta: Grasindo Ovretveit. (1998). Evaluating Health Interventions: Introduction to Evaluation of Health Treatments, Services Policies and Organizational Interventions, Sweden: McGraw -Hill Education

Kurniawan. H. (2016). Kreatif Mendongeng untuk Kecerdasan Jamak Anak. Jakarta: Kencana

Trelease.J. (2017). The Read Aloud Handbook. Jakarta: Noura 